\title{
Predictors of Mortality among Adult Antiretroviral Therapy Users in Southeastern Ethiopia: Retrospective Cohort Study
}

\author{
Tesfaye Setegn, ${ }^{1}$ Abulie Takele, ${ }^{2}$ Tesfaye Gizaw, ${ }^{3}$ Dabere Nigatu, ${ }^{2}$ and Demewoz Haile ${ }^{4}$ \\ ${ }^{1}$ Department of Reproductive Health, School of Public Health, College of Medicine and Health Sciences, Bahir Dar University, Ethiopia \\ ${ }^{2}$ Department of Nursing, College of Medicine and Health Sciences, Madawalabu University, P.O. Box 302, 1000 Bale Goba, Ethiopia \\ ${ }^{3}$ Department of Medicine, College of Medicine and Health Sciences, Madawalabu University, P.O. Box 302, 1000 Bale Goba, Ethiopia \\ ${ }^{4}$ Department of Public Health, College of Medicine and Health Sciences, Madawalabu University, P.O. Box 302, \\ 1000 Bale Goba, Ethiopia
}

Correspondence should be addressed to Demewoz Haile; demewozhaile@yahoo.com

Received 20 October 2014; Revised 31 January 2015; Accepted 15 February 2015

Academic Editor: David Katzenstein

Copyright (C) 2015 Tesfaye Setegn et al. This is an open access article distributed under the Creative Commons Attribution License, which permits unrestricted use, distribution, and reproduction in any medium, provided the original work is properly cited.

Background. Although efforts have been made to reduce AIDS-related mortality by providing antiretroviral therapy (ART) services, still people are dying while they are on treatment due to several factors. This study aimed to investigate the predictors of mortality among adult antiretroviral therapy (ART) users in Goba Hospital, Southeast Ethiopia. Methods. The medical records of 2036 ART users who enrolled at Goba Hospital between 2007 and 2012 were reviewed and sociodemographic, clinical, and ART-related data were collected. Multivariable Cox proportional hazards regression model was used to measure risk of death and identify the independent predictors of mortality. Results. The overall mortality incidence rate was 20.3 deaths per 1000 person-years. Male, bedridden, overweight/obese, and HIV clients infected with TB and other infectious diseases had higher odds of death compared with their respective counterparts. On the other hand, ART clients with primary and secondary educational level and early and less advanced WHO clinical stage had lower odds of death compared to their counterparts. Conclusion. The overall mortality incidence rate was high and majority of the death had occurred in the first year of ART initiation. Intensifying and strengthening early ART initiation, improving nutritional status, prevention and control of $\mathrm{TB}$, and other opportunistic infections are recommended interventions.

\section{Introduction}

Antiretroviral therapy (ART) has drastically improved the survival of patients who suffer from HIV/AIDS [1]. The primary goals of ART are as follows: maximal and durable suppression of viral replication, restoration of immunologic function, reduction of HIV-related morbidity and mortality, improvement of quality of life, and prolonging survival $[2,3]$. Global commitment to scale up HIV treatment in resourcelimited settings is bearing fruit. The fast growth in ART coverage represents one of the great public health success stories in recent history of HIV care that lead to reduction of mortality and improvement of quality of life of people living with HIV/AIDS (PLWHA) [1,3].

The government of Ethiopia has been working on the scaling up of ART for all people to reduce AIDS-related morbidity and mortality. Ethiopian Ministry of Health (MOH) introduced ART since 2003 on subsidized, fee-based scheme and has developed national guidelines on the use of ART. Since 2005, ART became freely available. Further, ART service was decentralized to health centers in 2006, which marked the rapid scale-up phase in the history of the Ethiopian ART program. In addition to adopting the World Health organization (WHO) recommended public health approach, Ethiopia used innovative models such as a nationwide campaign to achieve national targets both for ART and HIV testing and counseling [4-6]. The recent government report indicated that there were 274,805 patients (69\% ART coverage) who were alive and on ART by mid-2012 [7]. ART in Ethiopia included Stavudine (D4T), Lamivudine (3TC), Nevirapine (NVP), Zidovudine (AZT), 3TC-NVP, D4T-3TC-Efavirenz (EFV), and AZT-3TC-EFV prescribed to $46 \%, 18 \%, 23 \%$, and $13 \%$, respectively [8]. 
Despite the scale-up of ART, early mortality is a major challenge. High rates of early mortality were reported from a number of Sub-Saharan African ART programs [9-11]. Age, sex, educational status, place of residence, WHO clinical stage, CD4, Hemoglobin, nutrition, functional status, and opportunistic infections have been associated with mortality among clients on ART [12-15].

However, those factors which contribute to the deaths of HIV-infected patients while on ART are not well explored particularly in Southeast Ethiopia. Therefore, this study aimed to investigate the predictors of mortality among adult ART users in Goba Hospital, Southeast Ethiopia.

\section{Methods}

2.1. Study Setting and Period. The study was conducted in Goba Hospital, which is one of the public Hospitals in Bale Zone, located in Goba town 444 kilometers Southeast of Addis Ababa. The hospital has four major departments and one ART clinic. The ART clinic was established in 2005/6 after the Ethiopian government launched free ART service. Currently the ART clinic is providing basic HIV care and treatment. The data collection was conducted from March to April 2013.

2.2. Study Design and Sampling Procedure. A retrospective cohort study was conducted on adult ART users. Both ART experienced and ART naïve clients who started treatment in the time frame from 2007 to 2012 (5 years retrospective follow-up) were included in the study.

Medical records of adults ( $>15$ years old) initiating ART between 2007 and 2012 were examined.

2.3. Data Collection and Quality Control. Data were extracted using the Federal Ministry of Health (FMOH) HIV care/ART follow-up format as a data extraction tool. The data were extracted by a trained hospital ART service data clerk. The data extraction format includes sociodemographic characteristics (age, sex, marital status, educational level, and occupational status), functional status, duration on ART (measured in months), nutritional status (measured by BMI), WHO clinical staging (from stage I to stage IV), and clinical and laboratory markers. Functional status (bedridden, ambulatory, and working) was recorded from the patients' card and measured based on the status of patient at initiation of ART. The data collection/extraction process was supervised by the investigators. All completed data were examined for clarity and consistency on daily basis before analysis.

2.4. Data Analysis. Data were checked for completeness and inconsistencies, coded, entered, cleaned, and analyzed using SPSS for Windows version 20.0 (IBM SPSS Statistics, IBM Corp., New York). Descriptive statistics such as median, interquartile range (IQR), and mean and standard deviation $( \pm S D)$ were used to summarize the characteristics of the cohort. Person time (years) contribution of each study participant was calculated by comparing ART initiation time and death as an outcome variable. All AIDS-related deaths (which might include deaths due to opportunistic infections secondary to poor adherence to both ART regimen and prophylactic antibiotics) were recorded. ART clients who were lost to follow-up, transferred out, and dropped out were considered as censored.

The Kaplan Meier (KM) curve with Log Rank test was used to describe the survival time of ART patients based on initial CD4 count and WHO clinical stage at initiation of ART. Bivariate and multivariable Cox proportional hazards regression models were used to identify predictors of mortality. Those variables found statistically significant in the bivariate analysis $(P<0.05)$ were entered into multivariable Cox proportional hazards regression model to identify the independent predictors (adjusted for potential confounders) of mortality and estimate the adjusted hazard ratios (AHR). Both crude and adjusted hazard ratios (HRs) with 95\% confidence intervals were reported. Variables which were statistically significant at $P$ value $<0.05$ were concluded as predictors of mortality among ART clients.

2.5. Concepts and Definitions of Variables. Duration of treatment and follow-up was time (in months) after initiation of ART. Clinical stages (I-IV) were defined based on the WHO classification for AIDS clients. Mortality/death was defined as any recorded AIDS-related deaths including deaths due to opportunistic infections secondary to delayed ART initiation and poor adherence to both ART regimen and prophylactic antibiotics. In this study a client was considered as lost to follow-up if he/she had not been seen for $\geq 1$ month but $<3$ months while dropped out clients were those lost to follow-up for $>3$ months. A client who is transferred to another health facility for care was considered as transferred out. Therefore, all ART clients who were lost to follow-up, transferred out, and dropped out were considered as censored. On the other hand, the concept of functional status of clients was labeled as follows: working, to refer to clients who are able to perform usual work in or out of the house; ambulatory, to refer to clients able to perform activities of daily living; and bedridden, designated to clients who are not able to perform activities of daily living.

Ethical Consideration. Ethical clearance was obtained from the Institutional Research Ethics Review Committee, Research and Community Service Directorate Office of Madawalabu University. Letter of permission was obtained from administrative body of Goba Hospital. All information collected from clients' cards was kept anonymous and confidential.

\section{Results}

3.1. Characteristics of ART Clients. In this cohort study a total of 2036 ART clients were included. More than half 1132 (55.6\%) were females and 904 (44.4\%) were males. Four hundred twelve $(20.2 \%)$ of the ART clients had no formal education. The median (IQR) age at ART initiation was 35 years $(\mathrm{IQR}=29-38)$. One thousand seven hundred six 
TABLE 1: Sociodemographic characteristics of ART clients, Goba Hospital, Southeast Ethiopia, 2013.

\begin{tabular}{|c|c|c|}
\hline $\begin{array}{l}\text { Sociodemographic } \\
\text { variables }\end{array}$ & Frequency & Percen \\
\hline \multicolumn{3}{|l|}{ Age (years) } \\
\hline $15-24$ & 179 & 8.8 \\
\hline $25-29$ & 393 & 19.3 \\
\hline $30-34$ & 419 & 20.6 \\
\hline $35-39$ & 572 & 28.1 \\
\hline $40-44$ & 220 & 10.8 \\
\hline$\geq 45$ & 253 & 12.4 \\
\hline \multicolumn{3}{|l|}{ Sex of participants } \\
\hline Male & 904 & 44.4 \\
\hline Female & 1132 & 55.6 \\
\hline \multicolumn{3}{|l|}{ Educational level } \\
\hline No education & 412 & 20.2 \\
\hline Primary & 689 & 33.8 \\
\hline Secondary & 801 & 39.3 \\
\hline Tertiary & 134 & 6.6 \\
\hline \multicolumn{3}{|l|}{ Occupational status } \\
\hline Merchant & 311 & 15.3 \\
\hline Day laborer & 302 & 14.8 \\
\hline Housewife & 535 & 26.3 \\
\hline Jobless & 257 & 12.6 \\
\hline Farmer & 231 & 11.3 \\
\hline Government employee & 259 & 12.7 \\
\hline Other* & 141 & 6.9 \\
\hline \multicolumn{3}{|l|}{ Marital status } \\
\hline Never married & 325 & 16.0 \\
\hline Married & 1176 & 57.8 \\
\hline Separated & 138 & 6.8 \\
\hline Divorced & 289 & 14.2 \\
\hline Widowed & 108 & 5.3 \\
\hline \multicolumn{3}{|l|}{ Religion } \\
\hline Orthodox & 1197 & 58.8 \\
\hline Muslim & 670 & 32.9 \\
\hline Protestant & 139 & 6.8 \\
\hline Others $^{\circledR}$ & 30 & 1.5 \\
\hline
\end{tabular}

${ }^{*}$ Students, construction workers, drivers, and servants, ${ }^{\circledR}$ Jehovah, wakefeta.

(57.8\%) and 1197 (58.8\%) of ART clients were married and orthodox Christian, respectively (Table 1).

About $1646(80.8 \%)$ of the clients were at working functional status during ART initiation. One thousand one hundred ninety-six (58.7\%) of clients initiated ART at WHO clinical stage III. The median baseline CD4 count was 121 per millimeter cube of blood (IQR = 64-169). The median baseline hemoglobin (HgB) was $13.6 \mathrm{mg} / \mathrm{dl}(\mathrm{IQR}=11 \mathrm{mg} / \mathrm{dl}-$ $14.6 \mathrm{mg} / \mathrm{dl})$. Three hundred eighty-three (43.3\%) of the clients were anemic at initiation of ART (Table 2).

In this study, out of the total of ART clients, $27.3 \%$ of them have been on ART for more than 60 months. Nearly half
TABLE 2: Clinical characteristics of ART clients, Goba Hospital, Southeast Ethiopia, 2013.

\begin{tabular}{|c|c|c|}
\hline Baseline $^{*}$ characteristics & Number & Percent \\
\hline \multicolumn{3}{|l|}{ Baseline functional status } \\
\hline Working & 1646 & 80.8 \\
\hline Ambulatory & 276 & 13.6 \\
\hline Bedridden & 114 & 5.6 \\
\hline \multicolumn{3}{|l|}{ WHO stage at ART initiation } \\
\hline WHO stage I & 422 & 20.7 \\
\hline WHO stage II & 304 & 14.9 \\
\hline WHO stage III & 1196 & 58.7 \\
\hline WHO stage IV & 114 & 5.6 \\
\hline \multicolumn{3}{|l|}{ Baseline CD4 count } \\
\hline$\leq 200$ & 1705 & 85.5 \\
\hline $201-300$ & 252 & 12.6 \\
\hline$>300$ & 37 & 1.9 \\
\hline Median CD4 $\left(\mathrm{mm}^{3}\right)(\mathrm{IQR})$ & $\begin{array}{c}121.0 \\
(169.0-64.0) \\
\mathrm{mm}^{3}\end{array}$ & \\
\hline \multicolumn{3}{|l|}{ Baseline HgB level } \\
\hline Anemic & 383 & 43.3 \\
\hline Nonanemic & 501 & 56.7 \\
\hline Median HgB (mg/dL) (IQR) & $13.6 \mathrm{mg} / \mathrm{dL}(1$ & /dL-14.6 mg/dL) \\
\hline \multicolumn{3}{|l|}{ Patient screened for TB } \\
\hline Yes & 1940 & 95.3 \\
\hline No & 96 & 4.7 \\
\hline \multicolumn{3}{|l|}{$\begin{array}{l}\text { TB coinfection at initiation of } \\
\text { ART }\end{array}$} \\
\hline Positive & 285 & 14.7 \\
\hline Negative & 1655 & 85.3 \\
\hline \multicolumn{3}{|l|}{ Baseline BMI } \\
\hline$<18.5$ & 11 & 1.3 \\
\hline $18.5-24.9$ & 756 & 88.6 \\
\hline$\geq 25.0$ & 86 & 10.1 \\
\hline Median weight (Kg) (IQR) & \multicolumn{2}{|c|}{$50.0 \mathrm{Kg}(57 \mathrm{Kg}-45 \mathrm{Kg})$} \\
\hline
\end{tabular}

${ }^{*}$ Baseline indicates measurements at initiation of ART.

1101 (54.1\%) were alive and on follow-up while 341 (16.7\%) and $474(23.3 \%)$ were lost/dropped out and transferred out, respectively.

There were 120 deaths in 5,912 person-years of retrospective follow-up. The overall mortality incidence rate was 20.3 deaths per 1000 person-years. Of the total 120 deaths, majority of $78(65.0 \%)$ occurred in the first year ( $<12$ months) of ART initiation while twenty-two (18.3\%) had died after they have been followed up for 12-24 months. The overall mean (95\% CI) survival time was 34.9 (95\% CI: 33.8-35.9) months after ART initiation (Figure 1).

The equality of survival distribution (based on Log Rank test) between different categories of initial CD4 count showed a statistically significant difference in survival of clients based on different categories of initial CD4 $\left(\chi^{2}=13.73\right.$, Df $=2$; $P$ value $<0.001$ ) (Figure 2). 


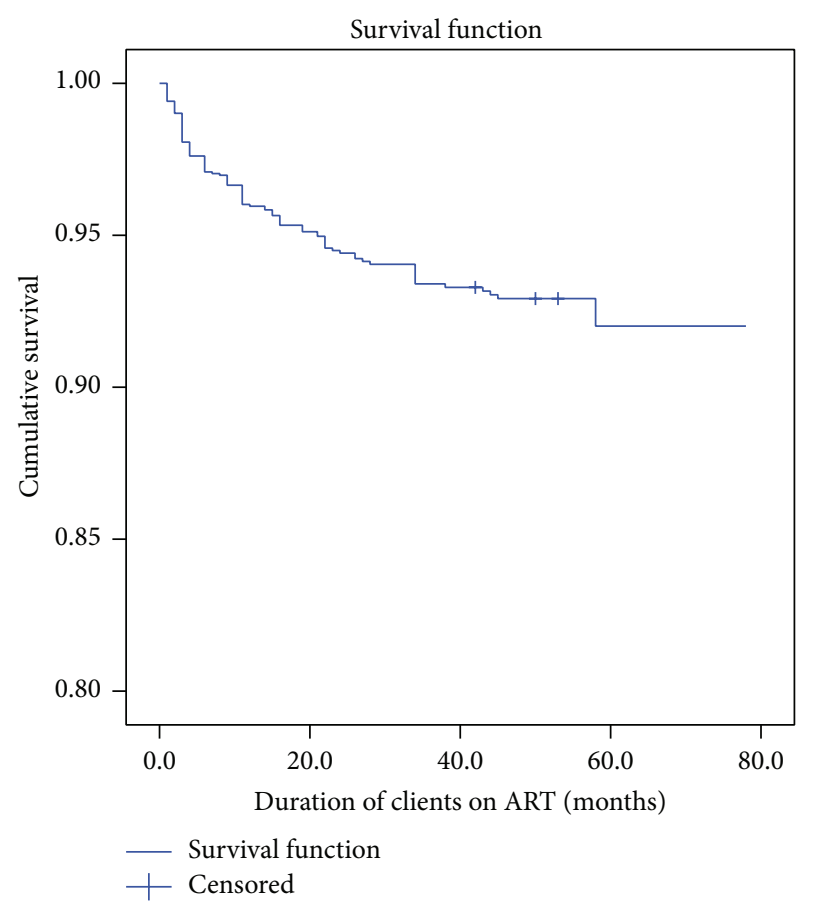

FIgURE 1: Survival among a cohort of ART clients, Goba Hospital, Southeast Ethiopia, 2013.

Similarly, the survival distribution of ART clients based on initial WHO clinical stage showed a statistically significant difference on Log Rank test $\left(\chi^{2}=40.01, \mathrm{Df}=3\right.$; $P$ value $<$ 0.001) (Figure 3).

3.2. Predictors of Mortality. In our study, multivariable Cox proportional hazards regression analysis showed that male ART clients, ambulatory clients, TB coinfected clients, individuals with baseline $\mathrm{BMI} \geq 25 \mathrm{~kg} / \mathrm{m}^{2}$, and clients who had opportunistic infection had higher odds of early death compared with their respective counterparts. On the other hand, higher educational status was associated with lower odds of early mortality compared to clients with no formal education. Similarly clients who had better baseline WHO clinical stages (I-III) had lower odds of early mortality compared to clients with baseline WHO clinical stage IV.

Male ART clients were 2.6 times more likely to experience early mortality while on ART treatment compared to females $($ AHR $=2.67 ; 95 \%$ CI: 1.74-4.10). Similarly, bedridden clients were 4.4 times more likely to die early as compared to clients with working functional status (AHR $=4.4$; 95\% CI: $1.55-$ 12.36). Those ART clients who are TB coinfected at ART initiation were 4.5 times more likely to experience early mortality (AHR $=4.51$; 95\% CI: 2.86-7.11). On the contrary, those ART clients with primary and secondary education had $72 \%(\mathrm{AHR}=0.28$; 95\% CI: $0.11-0.70)$ and $66 \%(\mathrm{AHR}=0.34$; 95\% CI: 0.154-0.728) lower odds of death as compared to clients with no formal education, respectively. Compared to WHO clinical stage IV, being at lower WHO clinical stages (IIII) was found to be protective of early mortality for clients on

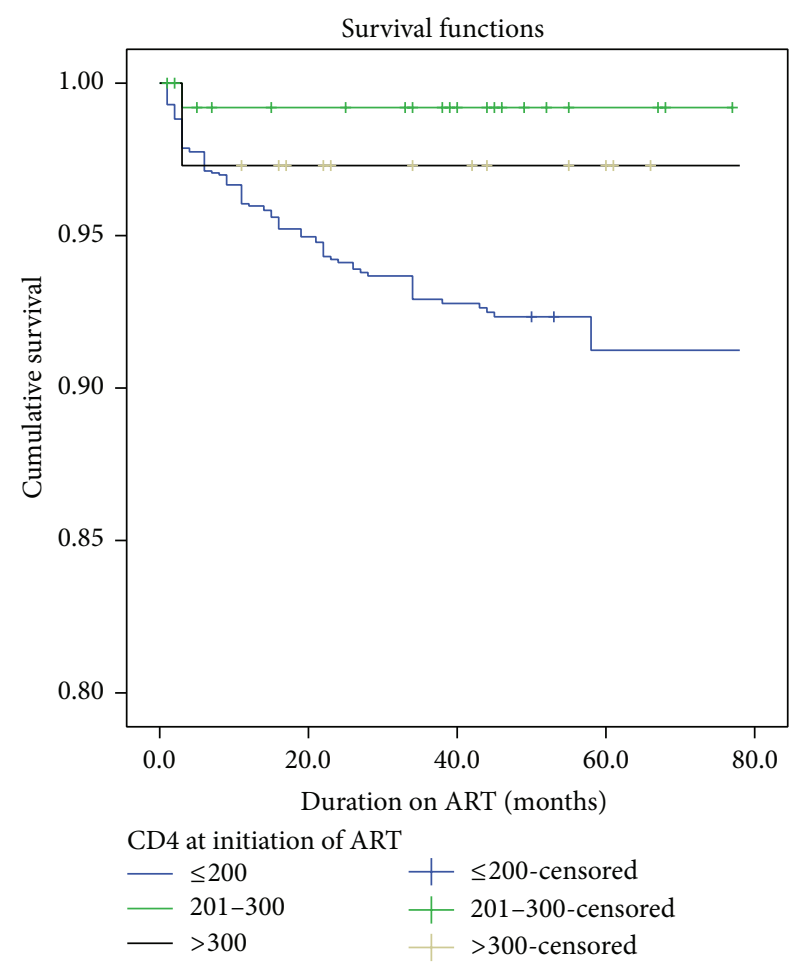

FIGURE 2: Survival function stratified according to initial recorded CD4 count among a cohort of ART clients, Goba Hospital, Southeast Ethiopia, 2013.

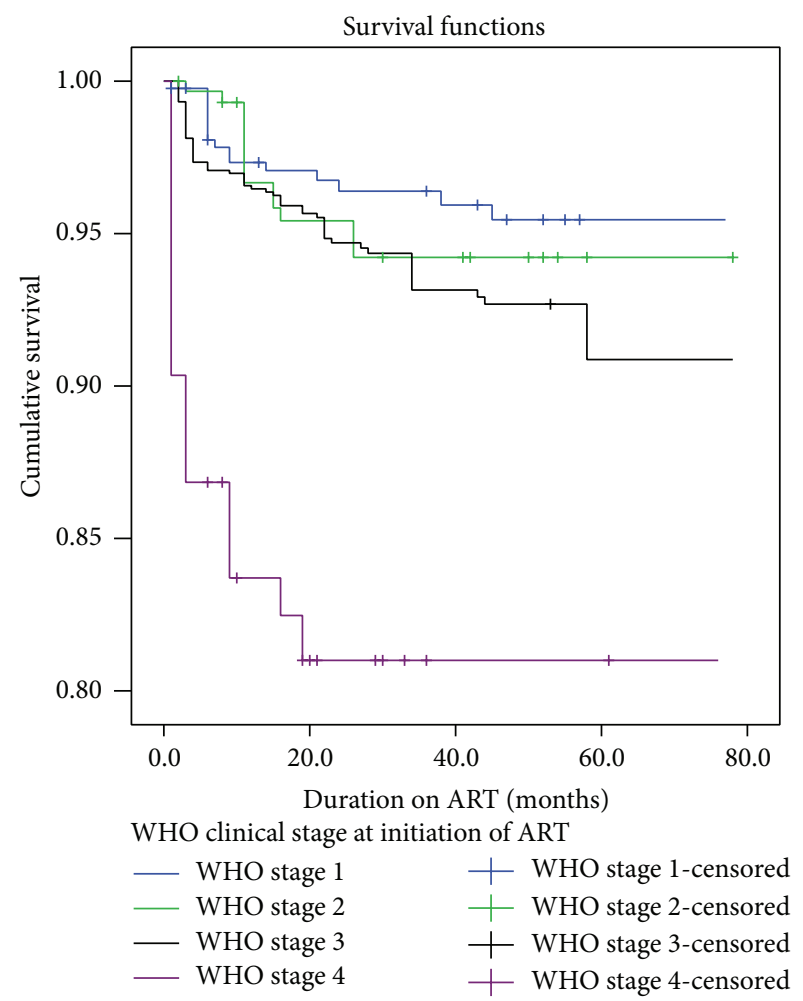

FIgURE 3: Survival function stratified according to initial WHO clinical stage among a cohort of ART clients; Goba hospital, Southeast Ethiopia; 2013. 
ART. ART clients with WHO clinical stages I, II, and III had $84 \%, 66 \%$, and $76 \%$ lower odds of early mortality compared with clients with WHO clinical stage IV. However, age of clients, CD 4 counts, and anemia status were not significantly associated with odds of death among ART clients (Table 3).

\section{Discussion}

In this study, there were 120 deaths among ART clients per 5,912 person-years of observation making the overall mortality rate 20.3 deaths per 1,000 person-years. This finding is similar to the finding from Eastern Ethiopia, which reported an overall mortality incidence rate of $2.03 / 100$ person-years [12], whereas studies conducted in rural public hospitals of Southern Nations, Nationalities, and People Regional (SNNPR) state of Ethiopia [16] and Arbaminch hospital [17] have reported higher mortality incidence rates which were 74.5 deaths per 1,000 and 15.4 deaths per 100 person-years, respectively.

Our study showed that majority (65\%) of the deaths occurred in the first year of ART initiation which was a similar finding with the study conducted in Arbaminch Hospital, Southern Ethiopia [10]. A study from Uganda showed that mortality rate in the first year of ART initiation was 12 deaths per 100 person-years [18]. Early and higher mortality of ART clients in this study was supported by different studies that revealed high early mortality in ART cohort that has been evidenced specially in resource-limited settings [11, 13, 19-21]. Deaths that occurred within the first early months of therapy might result from treatment failure, severe drug toxicity, and regimen changes [22].

Regarding the factors associated with mortality of ART clients, the Cox regression analysis showed that male ART clients were more likely to die compared to female ART clients. This finding is similar to several studies $[11,14,16,18$, 21, 23-26]. The possible reason for higher risk of mortality among male ART clients might be due to the observed significant difference in the proportion of baseline CD4 count (CD4 at initiation ART) $<200 / \mathrm{mm}^{3}(P<0.001)$ between males and females $(90.5 \%$ versus $81.6 \%)$. The other possible explanation for higher risk of mortality in males might be due to the males' behavioral factors like substance use [27-31].

In our study, those ART clients with higher educational status (primary and secondary education) had lower odds of death compared to those ART clients with no formal education. Many studies documented that higher educational status was associated with lower risk of mortality among ART users [15, 32, 33]. Likewise, those bedridden clients at initiation of ART were more likely to die compared to working functional status clients. In this regard, studies from Nepal and Ethiopia reported supporting evidences that poor baseline performance scale (being bedridden) was a predictor of mortality during ART care $[12,21,34]$. In the same way, WHO clinical stages (I-III) were associated with lower odds of death as compared to clients with WHO clinical stage IV. This indicated that advanced baseline WHO clinical stage was statistically significant clinical predictor of mortality as comparably documented by different studies $[11,12,14,16$,
TABLE 3: Cox regression model: Selected sociodemographic and clinical factors associated with mortality of ART clients in Goba Hospital, Southeast Ethiopia, 2013.

\begin{tabular}{|c|c|c|}
\hline \multirow[b]{2}{*}{ Variables } & \multicolumn{2}{|c|}{ Death as an outcome } \\
\hline & $\begin{array}{c}\text { Unadjusted } \\
\text { HR } \\
(95 \% \mathrm{CI})\end{array}$ & $\begin{array}{c}\text { Adjusted } \\
\text { HR } \\
(95 \% \mathrm{CI})\end{array}$ \\
\hline \multicolumn{3}{|l|}{ Sex of participants } \\
\hline Male & $\begin{array}{c}3.60 \\
(2.40-5.30)^{*}\end{array}$ & $\begin{array}{c}2.67 \\
(1.74-4.10)^{* *}\end{array}$ \\
\hline Female & 1.0 & 1 \\
\hline \multicolumn{3}{|l|}{ Educational level } \\
\hline No formal education & 1.0 & 1.0 \\
\hline Primary & $\begin{array}{c}0.34 \\
(0.13-0.84)^{*}\end{array}$ & $\begin{array}{c}0.28 \\
(0.11-0.70)^{* *}\end{array}$ \\
\hline Secondary & $\begin{array}{c}0.65 \\
(0.31-1.39)\end{array}$ & $\begin{array}{c}0.34 \\
(0.15-0.73)^{* *}\end{array}$ \\
\hline Tertiary & $\begin{array}{c}1.53 \\
(0.77-3.05)\end{array}$ & $\begin{array}{c}0.71 \\
(0.34-1.46)\end{array}$ \\
\hline \multicolumn{3}{|l|}{ Functional status } \\
\hline Working & 1.0 & \\
\hline Ambulatory & $\begin{array}{c}1.11 \\
(0.41-3.05)\end{array}$ & $\begin{array}{c}1.62 \\
(0.55-4.75)\end{array}$ \\
\hline Bedridden & $\begin{array}{c}4.99 \\
(1.80-13.88)^{*}\end{array}$ & $\begin{array}{c}4.38(1.55- \\
12.36)^{* *}\end{array}$ \\
\hline \multicolumn{3}{|l|}{ Baseline WHO stage } \\
\hline WHO stage 1 & $\begin{array}{c}0.17 \\
(0.09-0.33)^{*}\end{array}$ & $\begin{array}{c}0.16(0.08- \\
0.33)^{* *}\end{array}$ \\
\hline WHO stage 2 & $\begin{array}{c}0.22 \\
(0.11-0.44)^{*}\end{array}$ & $\begin{array}{c}0.34 \\
(0.16-0.73)^{* *}\end{array}$ \\
\hline WHO stage 3 & $\begin{array}{c}0.30 \\
(0.18-0.49)^{*}\end{array}$ & $\begin{array}{c}0.24 \\
(0.13-0.43)^{* *}\end{array}$ \\
\hline WHO stage 4 & 1.0 & \\
\hline \multicolumn{3}{|l|}{ Baseline CD4 count } \\
\hline$\leq 200$ & $2.5(0.3-17.6)$ & \\
\hline $201-300$ & $\begin{array}{c}0.3 \\
(0.03-3.20)\end{array}$ & - \\
\hline$>300$ & 1.0 & \\
\hline \multicolumn{3}{|l|}{ TB coinfection } \\
\hline Positive & $4.7(3.2-6.8)^{*}$ & $\begin{array}{c}4.51 \\
(2.86-7.11)^{* *}\end{array}$ \\
\hline Negative & 1.0 & 1 \\
\hline \multicolumn{3}{|l|}{ Anemia status } \\
\hline Anemic & $\begin{array}{c}0.25 \\
(0.04-1.52)\end{array}$ & - \\
\hline Nonanemic & 1.0 & \\
\hline \multicolumn{3}{|l|}{ Baseline BMI $\left(\mathrm{kg} / \mathrm{m}^{2}\right)$} \\
\hline$<18.5$ & $\begin{array}{c}1.83 \\
(1.20-2.77)^{*}\end{array}$ & $\begin{array}{c}1.20 \\
(0.77-1.87)\end{array}$ \\
\hline $18.5-24.99$ & 1.0 & \\
\hline$\geq 25.0$ & $\begin{array}{c}3.19 \\
(1.61-6.36)^{*}\end{array}$ & $\begin{array}{c}3.71 \\
(1.81-7.59)^{* * *}\end{array}$ \\
\hline \multicolumn{3}{|l|}{ Opportunistic infection } \\
\hline Yes & $\begin{array}{c}6.27 \\
(4.12-9.54)^{*}\end{array}$ & $\begin{array}{c}2.51 \\
(1.46-4.31)^{* *}\end{array}$ \\
\hline No & 1.0 & \\
\hline
\end{tabular}


TABLe 3: Continued.

\begin{tabular}{|c|c|c|}
\hline \multirow[b]{2}{*}{ Variables } & \multicolumn{2}{|c|}{ Death as an outcome } \\
\hline & $\begin{array}{c}\text { Unadjusted } \\
\text { HR } \\
(95 \% \text { CI }) \\
\end{array}$ & $\begin{array}{c}\text { Adjusted } \\
\text { HR } \\
(95 \% \mathrm{CI})\end{array}$ \\
\hline \multicolumn{3}{|l|}{ Age group } \\
\hline $15-30$ years & $\begin{array}{c}1.47 \\
(0.88-2.45)\end{array}$ & \\
\hline $31-40$ years & $\begin{array}{c}0.84 \\
(0.49-1.42)\end{array}$ & - \\
\hline$\geq 41$ years & 1.0 & \\
\hline
\end{tabular}

HR: hazard ratio; ${ }^{*}$ statistically significant at $P<0.05$ at the unadjusted HR model; ${ }^{* *}$ statistically significant at $P<0.05$ at the adjusted HR model (both 2 tailed).

$25,35,36]$. In our study, apart from advanced WHO clinical stage, TB coinfection at ART initiation was significantly associated with higher odds of mortality among ART clients as analogously reported by various studies [14, 18, 25, 35, 37]. ART clients who had BMI $\geq 25 \mathrm{Kg} / \mathrm{m}^{2}$ had higher odds of mortality compared with clients with normal BMI (18.5$24.9 \mathrm{Kg} / \mathrm{m}^{2}$ ) category. Higher odds of death among obese ART clients might be associated with other chronic diseases related to overweight and obesity such as hypertension, diabetes mellitus, and others. Although different studies documented that anemia is a statistically significant predictor of mortality of ART clients [13-15, 25, 34-36], this study did not find statistically significant association between anemia and mortality of ART clients.

This study should be interpreted in light of its strengths and limitations. Relatively larger sample size from long period of retrospective follow-up and the use of both clinical and nonclinical data were the strengths of this study. As a limitation, this study used routinely collected health care data which might have been introduced under estimation of mortality due to many unreported/home deaths. On the other hand, since the data were secondary data, authors could not ascertain that all recorded deaths were AIDS-related deaths (which might include deaths due to opportunistic infections secondary to poor adherence to both ART regimen and prophylactic antibiotics). The analysis was restricted only on the variables recorded on the clients' card. Therefore, interpretation and conclusion of finding should take these limitations into account.

\section{Conclusion}

The overall mortality incidence rate was 20.3 deaths per 1000 person-years. The presence of TB coinfection, WHO clinical stage, being bedridden, educational status, presence of opportunistic infections, and being overweight and obese were factors associated with mortality among ART clients. Initiation of ART at early WHO clinical stage, improving nutritional status, prevention and control of $\mathrm{TB}$, and other opportunistic infections were the recalled recommendations to decrease AIDS-related morality.
Abbreviations
AIDS: Acquired immunodeficiency syndrome
ART: Antiretroviral therapy
FDRE: Federal Democratic Republic of Ethiopia
HgB: Hemoglobin
HIV: Human immunodeficiency virus
IQR: Interquartile range
MOH: Ministry of Health
PLWHA: People living with HIV/AIDS
RCSDO: Research and Community Service
\begin{tabular}{ll} 
TB: & Directorate Office \\
WHO: & Wuberculosis \\
\hline
\end{tabular}

\section{Conflict of Interests}

The authors declare that they have no competing interests.

\section{Authors' Contribution}

Tesfaye Setegn conceived the idea of the study, managed data collection, analyses, and interpretation, and critically reviewed the paper. Abulie Takele conceptualized and assisted with design of the study as well as data interpretation and critical review of the paper. Tesfaye Gizaw managed data collection, assisted the data analysis, and critically reviewed the paper. Dabere Nigatu assisted with conceptualization of the study and data interpretation and critically reviewed the paper. Demewoz Haile assisted with the study design, analyses, and interpretation, drafted, and critically revised the paper. All authors read and approved the final paper.

\section{Acknowledgments}

The authors acknowledge Madawalabu University for funding this study. Their gratitude also goes to Goba Hospital, to the data clerk for collecting the data and study participants.

\section{References}

[1] I. Wanyeki, D. Cole, G. Sills, and P. Bass, "Five year survival probabilities after ART start at 3 hospitals in Guyana," in Proceedings of the Caribbean HIV Conference, 2011.

[2] UNAIDS/WHO, AIDS Epidemic Update 2007, 2007, http://data .unaids.org/pub/EPISlides/2007/2007_epiupdate_en.pdf.

[3] FMOH, Guidelines for Use of Antiretroviral Drugs in Ethiopia, 2005.

[4] FMOH, Monthly HIV Care and ART Update, 2006.

[5] FDRE, Report on Progress towards Implementation of the UN Declaration of Commitment on HIV/AIDS, FDRE, 2008.

[6] Y. Assefa, D. Jerene, S. Lulseged, G. Ooms, and W. van Damme, "Rapid scale-up of antiretroviral treatment in Ethiopia: successes and system-wide effects," PLoS Medicine, vol. 6, no. 4, Article ID e1000056, 2009. 
[7] Federal HIV/AIDS Prevention and Control Office, Monitoring and Evaluation Report, 2011/2012, FHAPCO, Addis Ababa, Ethiopia, 2013.

[8] Federal Ministry of Health, National Guidelines for Antiretroviral Treatment in Ethiopia, Federal HIV/AIDS Prevention and Control Office (HAPCO), Addis Ababa, Ethiopia, 2007.

[9] P. MacPherson, M. Moshabela, N. Martinson, and P. Pronyk, "Mortality and loss to follow-up among HAART initiators in rural South Africa," Transactions of the Royal Society of Tropical Medicine and Hygiene, vol. 103, no. 6, pp. 588-593, 2009.

[10] Z. Mulissa, D. Jerene, and B. Lindtjørn, "Patients present earlier and survival has improved, but pre-ART attrition is high in a six-year HIV cohort data from Ethiopia," PLoS ONE, vol. 5, no. 10, Article ID e13268, 2010.

[11] S. D. Lawn, A. D. Harries, X. Anglaret, L. Myer, and R. Wood, "Early mortality among adults accessing antiretroviral treatment programmes in sub-Saharan Africa," AIDS, vol. 22, no. 15, pp. 1897-1908, 2008.

[12] S. Biadgilign, A. A. Reda, and T. Digaffe, "Predictors of mortality among HIV infected patients taking antiretroviral treatment in Ethiopia: a retrospective cohort study," AIDS Research and Therapy, vol. 9, article 15, 2012.

[13] A. Johannessen, E. Naman, B. J. Ngowi et al., "Predictors of mortality in HIV-infected patients starting antiretroviral therapy in a rural hospital in Tanzania," BMC Infectious Diseases, vol. 8, article 52, 2008.

[14] V. Poka-Mayap, E. W. Pefura-Yone, A. P. Kengne, and C. Kuaban, "Mortality and its determinants among patients infected with HIV-1 on antiretroviral therapy in a referral centre in Yaounde, Cameroon: a retrospective cohort study," British Medical Journal, vol. 3, no. 7, Article ID e003210, 2013.

[15] K. Tadesse, F. Haile, and N. Hiruy, "Predictors of mortality among patients enrolled on antiretroviral therapy in Aksum hospital, Northern Ethiopia: a retrospective cohort study," PLoS ONE, vol. 9, no. 1, Article ID e87392, 2014.

[16] E. Tsegaye and A. Worku, "Assessment of antiretroviral treatment outcome in public hospitals, South Nations Nationalities and Peoples Region, Ethiopia," Ethiopian Journal of Health Development, vol. 25, no. 2, pp. 102-109, 2011.

[17] D. Jerene, A. Næss, and B. Lindtjørn, "Antiretroviral therapy at a district hospital in Ethiopia prevents death and tuberculosis in a cohort of HIV patients," AIDS Research and Therapy, vol. 3, no. 1, article 10, 2006.

[18] B. Amuron, J. Levin, J. Birunghi et al., "Mortality in an antiretroviral therapy programme in Jinja, south-east Uganda: a prospective cohort study," AIDS Research and Therapy, vol. 8, article 39, 2011.

[19] J. S. A. Stringer, I. Zulu, J. Levy et al., "Rapid scale-up of antiretroviral therapy at primary care sites in Zambia: feasibility and early outcomes," Journal of the American Medical Association, vol. 296, no. 7, pp. 782-793, 2006.

[20] P. J. Weidle, S. Malamba, R. Mwebaze et al., "Assessment of a pilot antiretroviral drug therapy programme in Uganda: patients' response, survival, and drug resistance," The Lancet, vol. 360, no. 9326, pp. 34-40, 2002.

[21] L. Bhatta, E. Klouman, K. Deuba et al., "Survival on antiretroviral treatment among adult HIV-infected patients in Nepal: a retrospective cohort study in far-western Region, 2006-2011," BMC Infectious Diseases, vol. 13, no. 1, article 604, 2013.
[22] N. Workneh, T. Girma, and M. Woldie, "Immunologic and clinical outcomes of children on HAART: a retrospective cohort analysis at Jimma University Specialized Hospital," Ethiopian Journal of Health Sciences, vol. 19, no. 2, pp. 75-82, 2009.

[23] F. Bajunirwe, E. Arts, D. Tisch, S. Debanne, and A. Sethi, "Survival, adherence to care and antiretroviral treatment (ART) among HIV-infected adults in rural Western Uganda," in Proceedings of the 4th IAS Conference on HIV Pathogenesis, Treatment and Prevention, abstract WEPEB049, International AIDS Society, Sydney, Australia, July 2007.

[24] K. Mageda, G. H. Leyna, and E. J. Mmbaga, "High initial HIV/AIDS-Related mortality and -its predictors among patients on antiretroviral therapy in the kagera region of Tanzania: a five-year retrospective cohort study," AIDS Research and Treatment, vol. 2012, Article ID 843598, 7 pages, 2012.

[25] A. Gupta, G. Nadkarni, W.-T. Yang et al., "Early mortality in adults initiating antiretroviral therapy (ART) in low- and middle-income countries (LMIC): a systematic review and meta-analysis," PLoS ONE, vol. 6, no. 12, Article ID e28691, 2011.

[26] K. Taylor-Smith, H. Tweya, A. Harries, E. Schoutene, and A. Jahn, "Gender differences in retention and survival on antiretroviral therapy of HIV-1 infected adults in Malawi," Malawi Medical Journal, vol. 22, no. 2, pp. 49-56, 2010.

[27] N. Hymowitz, K. M. Cummings, A. Hyland, W. R. Lynn, T. F. Pechacek, and T. D. Hartwell, "Predictors of smoking cessation in a cohort of adult smokers followed for five years," Tobacco Control, vol. 6, pp. S57-S62, 1997.

[28] K. Steyn, D. Bradshaw, R. Norman, R. Laubscher, and Y. Saloojee, "Tobacco use in south Africans during 1998: the first demographic and health survey," Journal of Cardiovascular Risk, vol. 9, no. 3, pp. 161-170, 2002.

[29] K. Jagoe, R. Edwards, F. Mugusi, D. Whiting, and N. Unwin, "Tobacco smoking in Tanzania, East Africa: population based smoking prevalence using expired alveolar carbon monoxide as a validation tool," Tobacco Control, vol. 11, no. 3, pp. 210-214, 2002.

[30] E. Rudatsikira, J. Dondog, S. Siziya, and A. S. Muula, "Prevalence and determinants of adolescent cigarette smoking in Mongolia," Singapore Medical Journal, vol. 49, no. 1, pp. 57-62, 2008.

[31] A. A. Reda, A. Moges, B. Yazew, and S. Biadgilign, "Determinants of cigarette smoking among school adolescents in eastern Ethiopia: a cross-sectional study," Harm Reduction Journal, vol. 9, article 39, 2012.

[32] S. I. Bello and O. A. Itiola, "Drug adherence amongst tuberculosis patients in the university of ilorin teaching hospital, ilorin, nigeria," African Journal of Pharmacy and Pharmacology, vol. 4, no. 3, pp. 109-114, 2010.

[33] I. Jarrin, B. Lumbreras, I. Ferreros, S. Pérez-Hoyos, I. Hurtado, and I. Hernández-Aguado, "Effect of education on overall and cause-specific mortality in injecting drug users, according to HIV and introduction of HAART,' International Journal of Epidemiology, vol. 36, no. 1, pp. 187-194, 2007.

[34] N. Abebe, K. Alemu, T. Asfaw, and A. A. Abajobir, "Survival status of hiv positive adults on antiretroviral treatment in Debre Markos Referral Hospital, Northwest Ethiopia: retrospective cohort study," Pan African Medical Journal, vol. 17, article 88, 2014.

[35] D. D. Cuong, A. Thorson, A. Sönnerborg et al., "Survival and causes of death among HIV-infected patients starting 
antiretroviral therapy in north-eastern Vietnam," Scandinavian Journal of Infectious Diseases, vol. 44, no. 3, pp. 201-208, 2012.

[36] G. Chalamilla, C. Hawkins, J. Okuma et al., "Mortality and treatment failure among HIV-infected adults in Dar Es Salaam, Tanzania," Journal of the International Association of Physicians in AIDS Care, vol. 11, no. 5, pp. 296-304, 2012.

[37] M. Ghate, S. Deshpande, S. Tripathy et al., "Mortality in HIV infected individuals in Pune, India," Indian Journal of Medical Research, vol. 133, no. 4, pp. 414-420, 2011. 


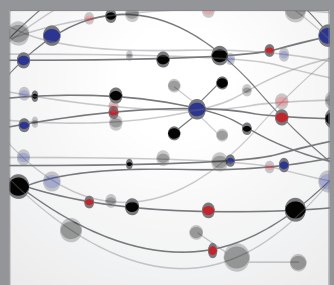

The Scientific World Journal
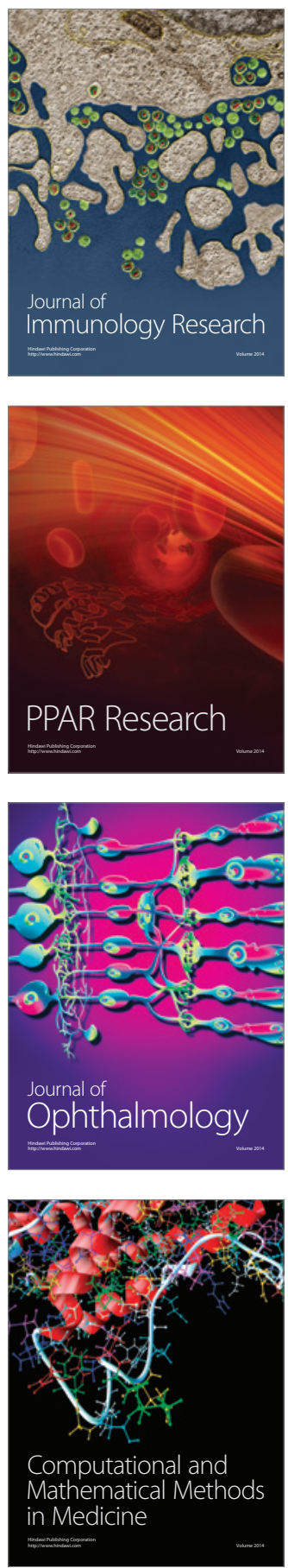

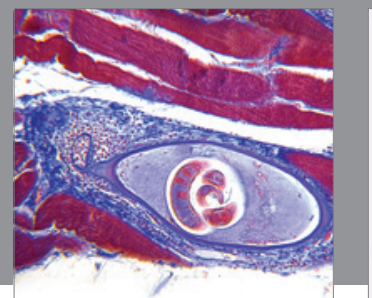

Gastroenterology

Research and Practice
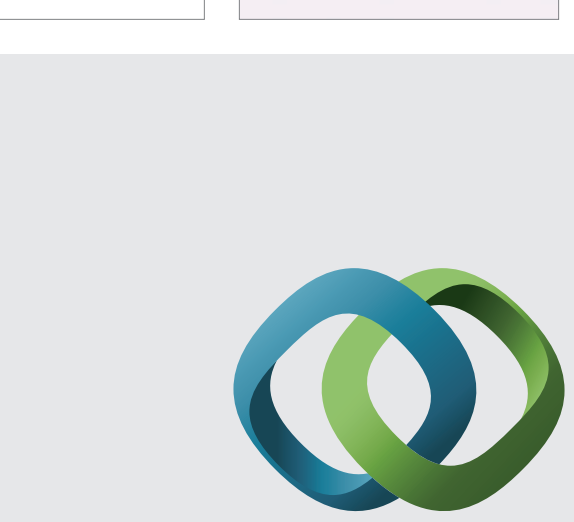

\section{Hindawi}

Submit your manuscripts at

http://www.hindawi.com
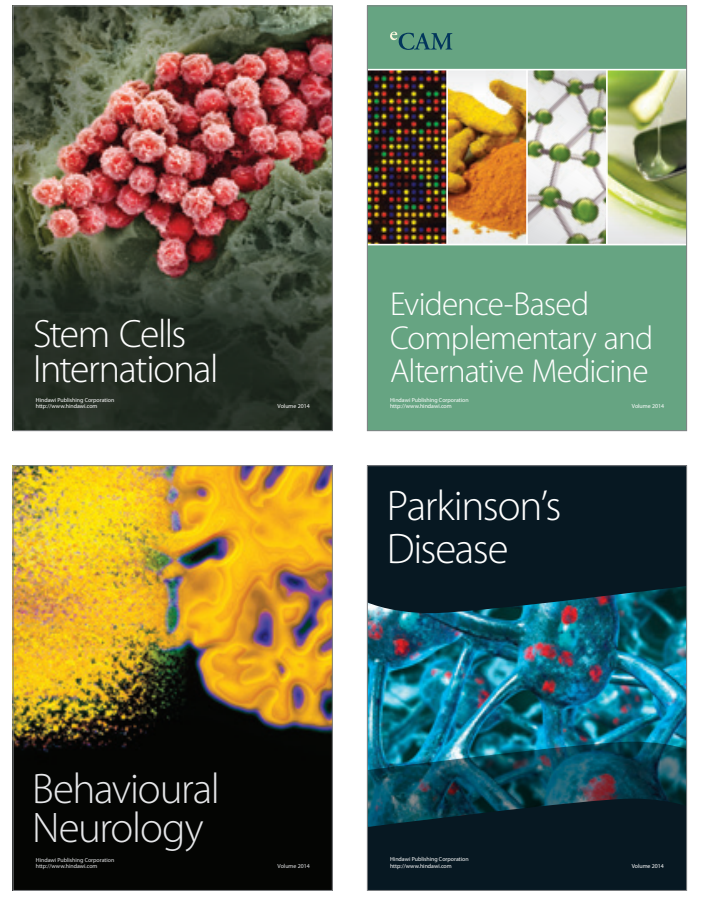
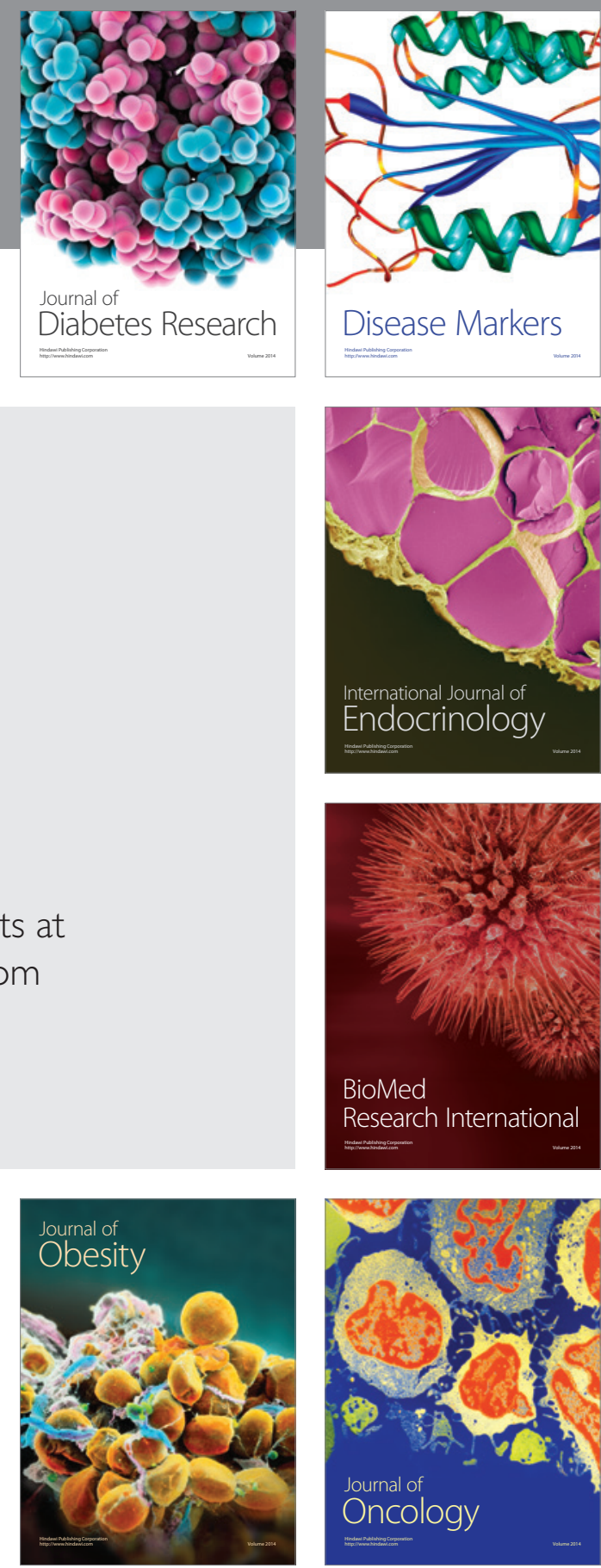

Disease Markers
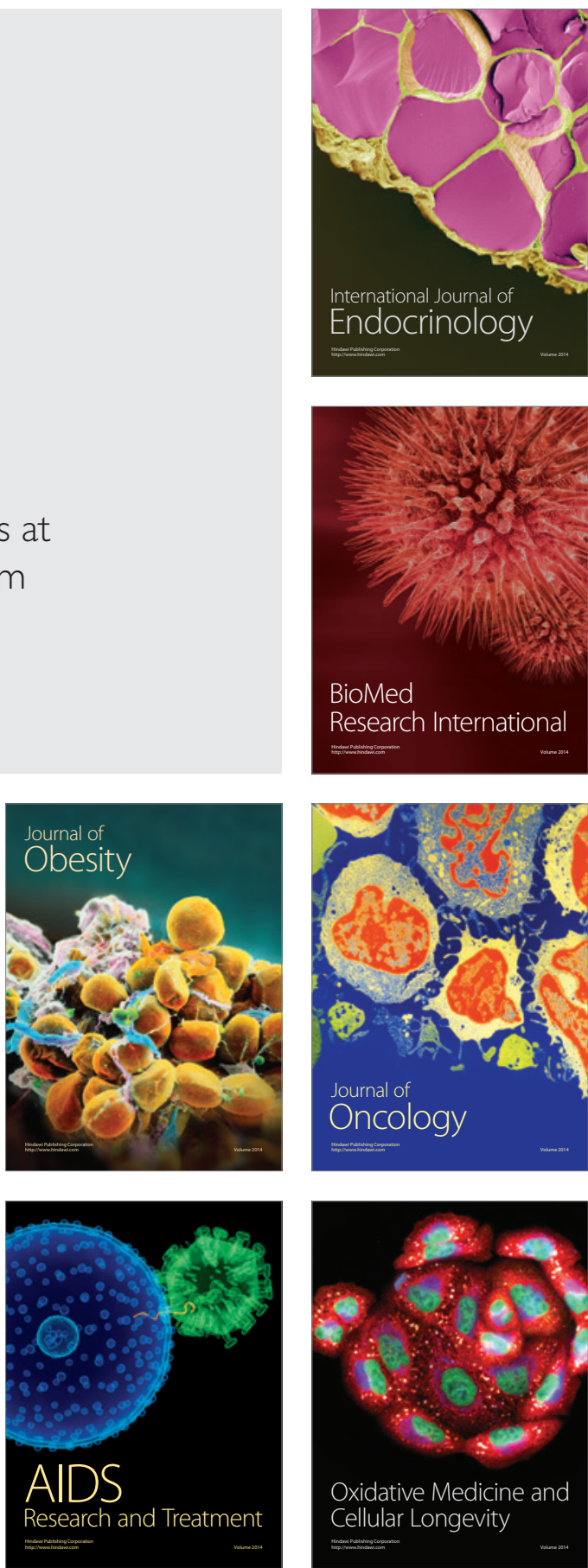